\title{
Demand Forecasting In the Maritime Industry, a Case of Maerskline Ghana
}

\author{
John Mensah \\ School of Business, Cape Coast Polytechnic, Cape Coast, Ghana \\ Stephen Kwasi Anim \\ School of Education, Southern New Hampshire University \\ Manchester, New Hampshire, USA \\ Frank Obeng \\ School of Business, Takoradi Polytechnic, Takoradi, Ghana \\ James Adu Peprah \\ School of Business, Takoradi Polytechnic, Takoradi, Ghana
}

\begin{abstract}
Demand forecasting is of critical essence to the maritime industry, especially in Ghana. On this note the study sought to achieve among other things by identifying the type(s) of model(s) used by Maritime industry in forecasting their operational demands as well as develop an appropriate forecasting model(s) for this industry using Maersk line as a case. We realized that Maersk line preferred to be responsive and as such incur more cost by underutilizing their capacity. Maersk line Ghana should not use only one model to forecast for both exports and import data. We therefore recommend from our study that the organization should use exponential smoothing model of forecasting to forecast their export data only.
\end{abstract}

Keywords: Demand forecasting, maritime, moving average, exponential smoothing

\section{INTRODUCTION}

Worldwide movement of goods is a critical element in the global freight transportation system that includes ocean and coastal routes, inland waterways, railways, roads, and air freight. However, international maritime transportation is more commonly a complement to other modes of transportation. This is particularly true for intercontinental containerized cargoes and for liquid and dry bulk cargoes, such as oil and grain. Here, international shipping connects roads, railways, and inland waterways through ocean and coastal routes (Corbett and Winebrake, 2008).

The maritime industry plays a very significant role in the socio-economic development of any country. Landlocked countries greatly depend on countries with ports and harbor facilities to either import or export their goods. This means that Ghana stand the chance to rake in additional revenue by serving landlocked countries like Burkina Faso, Niger, Mali and the likes if the country and an agencies like Maersk line Ghana are able to put up with good maritime facilities as well as providing efficient and effective maritime services.

Shipping has been an important human activity throughout history, particularly where prosperity depended primarily on international and interregional trade. In fact, transportation 
has been called one of the four cornerstones of globalization, along with communications, international standardization, and trade liberalization (Kumar and Hoffmann, 2002)

The maritime industry includes all enterprises involved in the business of designing, constructing, acquiring, operating, supplying, repairing and maintaining vessels or component parts thereof. It also includes managing and/or operating shipping lines, custom brokerages services, shipyards, shipping and freight forwarding services and similar enterprises. This means that the industry is very wide and can have the capacity to generate a lot of direct and indirect jobs. But the question is that, can Ghana take advantage of the opportunities that abound in the maritime industry?

One of the major reasons why Ghana has failed to take advantage of its ports and harbors in Tema and Takoradi to serve the needs of neighboring landlocked countries is the failure in planning the immediate service provision capacity and assessing the investments required to scale up in order to meet future demands. Good forecasting underpins many of this decisions. In the light of these discussions, there is the need for the service sector, precisely the maritime industry to focus on demand forecasting in order to meet demand. This study concentrated mainly on demand forecasting for the maritime industry.

Demand forecasting is the area of predictive analytics dedicated to understanding consumer demand for goods or services. Many decisional processes, such as capacity planning, inventory management, product development, production and supply chain planning, require forecasting. In recent times, demand has tended to become more variable and uncertain in many services. Managing such uncertain demand has posed significant problems for some industrial sectors including maritime industry.

Demand forecasting is of critical essence to the maritime industry, especially in Ghana, due to the recent discovery and production of crude oil in commercial quantities. Shipping companies will have to forecast accurately in order to make appropriate capacity available to transport the oil. The growth of every industry and survival depends on how well it can forecast demand and make the required capacity available in order to fully satisfy demand. Every economy's growth depends on the development of the industry, and Ghana is no exception.

The maritime industry is not merely a service rendering sector but also an economic management entity whose efficiency is central to effective national development and thus the difficulties encountered in the implementation of demand forecasting and capacity planning, how little or no importance has been placed on the concept, and little studies conducted in this area caused us to research into demand forecasting in the maritime industry using Maersk Ghana Limited as the area of study to assess demand forecasting on their activities and suggest possible ways of improving the adverse effects in the industry.

Essentially, businesses have been concerned about the disruptions that increase travel times between ports and ultimately affect the deliveries in one or more time windows. It is argued that rather than attempt to eliminate delay in maritime industry, policy makers should formulate public policy initiatives that minimize the levels of delays and its undesirable outcomes. The premises for such a policy direction are that to find an optimal schedule for a pool of ships that deliver a product from a set of loading ports to a set of discharging ports such that constraints related to inventory storage at loading ports and contractual obligations at discharging ports are satisfied. 
Thus, the central motivation of this research is to contribute to transportation research by advancing knowledge on the underlying causal mechanisms that link forecasting to the shipping activities, the contingency factors that amplifies optimal routing plan that minimizes the total cost of transportation, while satisfying inventory constraints and contractual delivery constraints.

The study then contends that flexible solutions can withstand unplanned disruptions. Therefore we consider disruptions that increase travel times between ports and ultimately affect the deliveries in one or more time windows. On this note the study sought to achieve among other things by identifying the type(s) of model(s) used by Maritime industry in forecasting their operational demands as well as develop an appropriate forecasting model(s) for these industry using Maersk line as a case study. Again, investigating the impact of the maritime industry model(s) of forecasting on their operational activities and then determine the essential link between demand forecasting and capacity planning of Maersk.

\section{Supply Chain and Planning}

\section{LITERATURE REVIEW}

Supply chain planning to a large degree, starts with forecasting. Supply chain planning involves functions such as demand forecasting and planning, distribution inventory planning, and plant capacity planning and scheduling. Supply Chain in the maritime industry is diverse in nature, ranging from high value, made to order items, to low value commodities items (Phelan \& McGarraghy, 2006) and this complicates demand forecasting. As such, it not only depends on a variety of macroeconomic factors that are not trivial to predict (oil prices, industrial growth, etc.), but is also heavily dependent on political developments, which are even more difficult to predict (Magirou et al, 1992).

\section{The Maritime Industry}

Maritime transport comprises of the maritime shipping and the ports dimensions, which are the most globalized industry, having assets present in every market. The global market is dominated by a few maritime shipping companies in close relationship with global terminal operators, (Rodrique 2010). The shipping companies are the front-runners of globalization (DNV 2004).

Sletmo (1989) identified four stages in the evolution of shipping, also known as 'waves' of evolution. This has expanded markets for raw materials and final products and has facilitated the industrializations of many countries around the world (Progoulaki, 2005).

\section{Maritime Industry and its Importance}

The maritime industry transports commercial goods more cost effectively than trucks and rails while providing the most environmentally sound mode of transportation. Marine transportation is widely recognized as the most environmentally friendly compared to other modes of freight transportation. In terms of fuel efficiency, for example, water borne barge transportation is $39 \%$ more fuel efficient than rail and $370 \%$ more efficient than trucks. The same holds true in terms of emissions. Based on ton miles traveled per ton of greenhouse gases (GHG) released, water transportation is similarly 39\% less damaging to the atmosphere than rail and $370 \%$ less damaging than trucks. The maritime industry is also continually seeking ways to further reduce its environmental impact. Industry initiatives to help protect our marine and ocean environments include the introduction of low-sulfur fuels, shutting down main engines in part to reduce emissions, and working with government officials to establish best navigation routes to minimize environmental impact (Krumwiede \& Sheu, 2002). This 
sometimes needs specialized containers, such as the high-pressure containers for natural gas (Tseng et al, 2005). A significant contribution from the industry could be seen from Information Handling Services (IHS) (2009), a recognized global leader in economic and financial analysis and forecasting, completed an evaluation of the economic contribution of one of the aspect of the maritime industry-using 2007 as a base year. Key findings includes annual economic contribution of US $\$ 183.3$ billion, creation of 4.2 million jobs, US $\$ 27.2$ billion in the form of compensation to those employees, direct capital expenditure of US $\$ 29.4$ billion.

\section{Meaning of Demand Forecasting}

Forecasting generally refers to knowing or measuring the status or nature of an event or variable before it occurs. Knowing the status of the effect is possible only when we know the status of its respective cause or causes, reason being that the effect will occur only when its cause or causes occur (Chendroyaperumal, 2009). Abdul and Chong, (2009) also asserted that demand forecasting includes the prediction, projection or estimation of expected demand of a product or service over a specified future time. Armstrong (2001) as well observed that forecasting is estimating in unknown situation. Prediction is a more general term and connotes estimating for anytime period before, during or after the current one. He concluded that forecasting is commonly used when discussing time series. Simply put, demand forecasting is the process of predicting the timing and amount of future requirements for goods and/or services. Recent definition of Nurrahman, (2012) posited that demand forecasting is the demand for products that are expected to be realized for a certain period in the future. Korpela and Tuominen,(1996) observed that forecasting the demand for products in the immediate future and over longer time periods is one of the most crucial issues in organizations.

\section{Importance of Demand Forecasting}

Rowe and Wright (2001) stated that there are two uses of forecasts. One is to help managers plan the system, and the other is to help them plan the use of the system. Huang and Lee (2011) comment that uncertainty is a fact of life and, therefore, a good forecast of future demand is necessary if proper planning for future level of production is to be made. In other words, most manufacturers "make to stock" rather than "make to order" - they plan ahead and then deploy inventories of finished goods into field locations. An order cycle could take weeks or months to go back through part suppliers and sub-assemblers, through manufacture of the product, and through to the eventual shipment of the order to the customer (Caplice, 2003). Further, to raise demand of its product or its market share, a firm can pursue other strategies such as properly adjusting its price policy or model of its product (Chan, 2000). Therefore, forecast of demand greatly helps in business decisions by reducing uncertainty under which firms operate (Wheelwright, 1989).

\section{Types of Demand Forecasting Techniques}

According to Jacobs and Chase,(2008)there are basically two main approaches to forecasting that is the explanatory method and the extrapolation method -with mainly two categories of forecasting, that is, quantitative and qualitative methods. Qualitative methods are based on judgments, opinions, intuition, emotions, or personal experiences and are subjective in nature (Whonder, 2009). With the Quantitative methods they are based on mathematical (quantitative) models, and are objective in nature (Armstrong, 2001).

\section{Exponential Smoothing}

The most widely used extrapolation method with the possible exception is exponential smoothing. It is sensible in that it weights recent data more heavily and, as a type of moving average, it smoothens out fluctuations. Therefore, this method finds widespread use in the business world, particularly when frequent and automatic forecasts of many items are 
required (Anderson et al 2012). Gardner (2006) reviewed the "state of the art" on exponential smoothing. According to Duell (2001), larger alpha values emphasize recent levels of demand and result in forecasts more responsive to changes in the underlying average. Smaller alpha values treat past demand more uniformly and result in more stable forecasts. Forecast errors tend to be better than the simple and weighted forecast methods (Duell, 2001). The general exponential equation formula is given by:

$$
F_{t+1}=\alpha Y_{t}+(1-\alpha) F_{t}
$$

Where $F_{t+1}=$ forecast of the time series for period $\mathrm{t}+1$

$Y_{t} \quad=$ actual value of the time series in period $\mathrm{t}$

$F_{t} \quad=$ forecast of the time series for period $\mathrm{t}$

$\alpha \quad=$ smoothing constant $(0 \leq \alpha \leq 1)$

\section{Moving Averages Models}

The moving averages method uses the average of the most recent data values in the time series as the forecast for the next period. The term moving is used because every time a new observation becomes available for the time series, it replaces the oldest observation in the equation and a new average is computed. This is the reason for the term moving averages. (Anderson et al 2012). The main criticism of the moving averages method is that it puts equal weight on each value in a typical moving average. Forecast errors tend to be larger than other methods (Duell 2001).

Formula is given as,

$$
\text { Moving average }=\frac{\left.\sum \text { (most recent } n \text { data values }\right)}{n}
$$

\section{Weighted Moving Averages}

Weighted moving averages involve selecting a different weight for each data value and then computing a weighted average of the most recent values as the forecast. In most cases, the most recent observation receives the most weight, and the weight decreases for older data values. (Anderson et al 2012). Forecast errors tend to be smaller than the Simple forecast, but still larger than other methods (Duell, 2001). The general formula for estimating the weighted moving average is given by:

$$
F_{t+1}=\frac{\sum(\text { weight in period } i)(\text { Actual value in period } i)}{\sum(\text { Weights })}
$$

\section{Measures of Forecast Accuracy}

The measures of forecast accuracy simply measure how well the forecasting method is able to forecast historical values of the time series. All forecasts contain errors. Forecasting errors are caused by not accurately predicting trends in demand and randomly occurring errors from unpredictable factors. To ensure that the correct method is utilized you need to measure the forecast error. The method that gives the least error is the best method (Gardner, 2006). Some of the techniques used are Mean absolute deviation/error (MAE/D), mean squared error (MSE) and mean absolute percentage error (MAPE) (Anderson et al, 2005).

\section{The Role of Information Technology Systems in Demand Forecasting}

Information systems play a very important role in the demand forecasting process. According to McMahon et al (1999), IT provides support for demand forecasting and communication activities. Most forecasting programs are fast and efficient data processors. They asserted that most operate seamlessly, taking good advantages of menus and dialogue boxes, and fully 
supporting both spreadsheets and balance sheets and databases. Many offer automatic forecast-method selection, which is especially useful when forecasting a large batch of time series (Tashman \& hoover, 2001). Information technology is ideal for automating these tasks and establishing a level of sophistication that would be available with manual means (McMahon et al., 1999). Examples, ranging from simple statistical methods to advanced causal methods include: Spreadsheets, General statistical packages, Specialist forecasting packages Enterprise resource planning (ERP) packages, Advanced Planning and scheduling (APS) Packaging, QM for windows software and others (Turban, et al., 2007).

\section{Why Forecasts are Inaccurate}

According to Gilliland (2011) forecasts never seem to be as accurate as we would like them to be or need them to be. As a result, we are tempted to throw money at the problem in hopes of making it go away. There are at least four kinds of reasons why our forecasts are not as accurate as we would like them to be. Unsuitable software - software that doesn't have the necessary capabilities, has mathematical errors, or uses inappropriate methods. It is also possible that the software is perfectly sound but due to untrained or inexperienced forecasters, it is misused.

The second reason is when untrained, unskilled, or inexperienced forecasters exhibit behaviors that affect forecast accuracy. One example is over-adjustment, or as W. Edwards Deming put it, "fiddling" with the process. This happens when a forecaster constantly adjusts the forecast based on new information. Research suggests that much of this fiddling makes no improvement in forecast accuracy and is simply wasted effort.

Forecasting should be a dispassionate and scientific exercise seeking a "best guess" at what is really going to happen in the future. The third reason for forecasting inaccuracy is process contamination by the biases, personal agendas, and ill-intentions of forecasting participants. Instead of presenting an unbiased best guess at what is going to happen, the forecast comes to represent what management wants to see happen - no matter what the marketplace is saying.

Finally, bad forecasting can occur because the desired level of accuracy is unachievable for the behavior being forecast. Consider calling heads or tails in the tossing of a fair coin. It doesn't matter that we may want to achieve 60,70 or 90 percent accuracy. The reality is that over a large number of tosses, we will only be right half of the time and nothing can change that. The nature of the behavior determines how well we can forecast it - and this applies to demand for products and services just as it does to tossing coins.

\section{METHODOLOGY}

Data collected were both quantitative and qualitative. The main data collection tools were Interview and the use of documentations. Primary data was obtained by conducting an interview with the case study institution- Maersk line Ghana. Secondary sources of data for this study were through documentations. According to Yin (2003), documents could be letters, memoranda, agendas, study reports, or any items that could add to the data base. In this study, secondary data relevant to the forecasting were taken from the Maersk line Ghana Limited. Data taken were past data kept by the Maersk line Ghana Limited. The data that were used for this study is the monthly shipping order unit.

\section{Types of Forecasting Models Used}

\section{DATA ANALYSIS AND DISCUSSION}

According to the management of Maersk line there are many techniques that the company employed to forecast their operations in order to carry out its functions effectively. In choosing 
the type of forecasting model, is always done by the top management that is operations and the marketing managers. According to management both the qualitative and quantitative approaches could be used in forecasting their shipping demand. However, the quantitative approach is usually adopted in forecasting. Some of the forecasting models used by Maersk are simple average and moving averages. It was also reviewed that new forecasting models were adopted to replace ineffective ones. They were previously using only the qualitative approach but realized they were always experiencing excess capacity and adopted the quantitative approach to forecast their demand. Some of the factors that lead to the review of their forecast models were the changes in market dynamics, fit- to- purpose, and source of data quality. In choosing a particular method of forecasting, Maersk involves the capacity and demand of third parties such as customers and other logistics firms that transport their freights as well as considering some factors like availability of historical data, the availability of computer software and the time needed to gather and analyze data and to prepare the forecast before selecting a forecasting technique.

\section{Developing an Appropriate Forecasting Method for Maersk Line.}

In order to develop an appropriate forecasting method for the Maersk line Ghana, time series data for the demand of their services over a period of 22 months, spanning from January 2010 to October 2011 were collected. The data were categorized into exporting and importing services. The division is necessary due to the fact that different factors affect the demand for citizens' exporting and importing services. The data obtained is presented in Figure 4.1. The first consideration to be made in developing a forecasting model is to identify the pattern exhibited by the time series data. The pattern exhibited by a time series data may be one of horizontal, trend, seasonal, cyclical or a combination of some of the patterns. In order to identify the trend of a time series data is important to construct a time series plot. Hope and Mühlemann (1997) asserted that for a forecast to be made, the pattern must be identified at a regular interval. In our study, the interval was in months. The trend of the data, which normally presents a random fluctuation, is then assessed and the inevitable deviation throughout the trend inspected, defined, evaluated and taken into account once future forecasting is done.

\section{ACTUAL DEMAND FOR MAERSK EXPORT SERVICES OVER THE STUDY PERIOD}

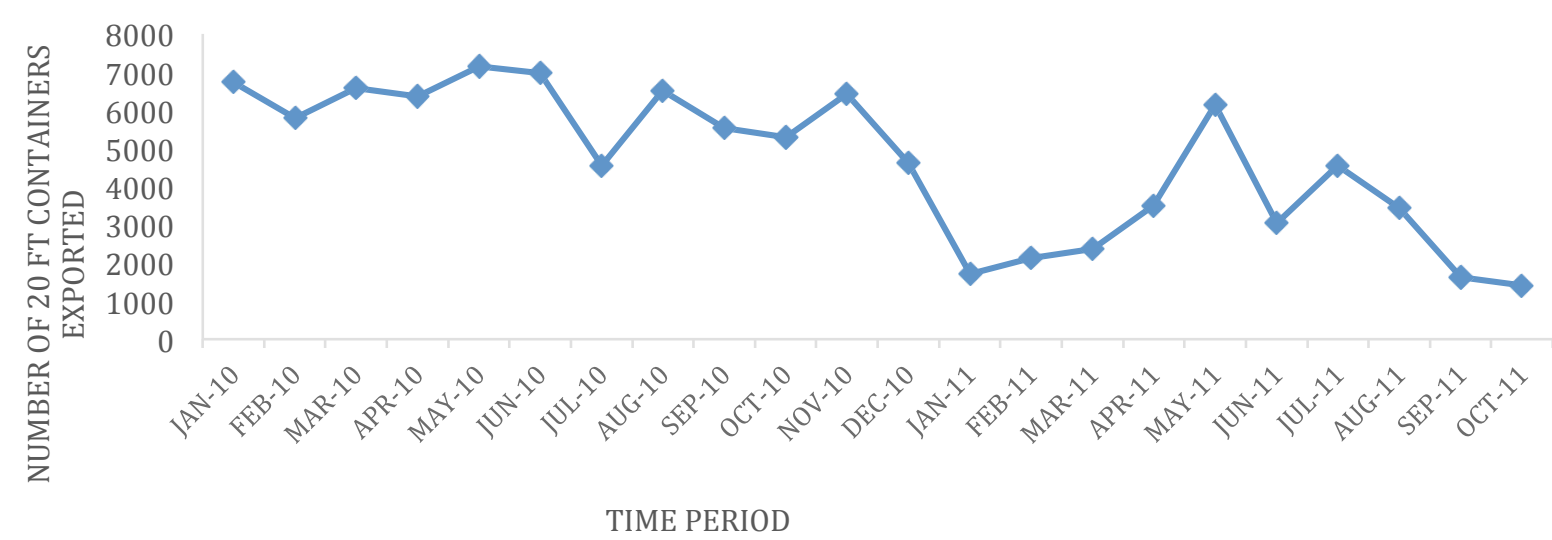

Figure 4.1: Time series plot of the demand for Maersk Line's export services over the study period.

The time series plot indicates more of a horizontal trend. As stated by Anderson et al (2012). A horizontal pattern exists when the data fluctuate around a constant mean. From the diagram, 
between the periods of Jan 2010 to December 2010, the demand of exports is relatively stable. There seems to be a decrease in the stability from the period of January 2011 upwards. However, the stability is restored from April 2011 through to August 2011. In general, the demand is relatively stable with occasional random variations. The existence of seasonality is not explicitly observed in the figure 4.1. However, there seems to be a general decrease in demand from January 2011 upwards.

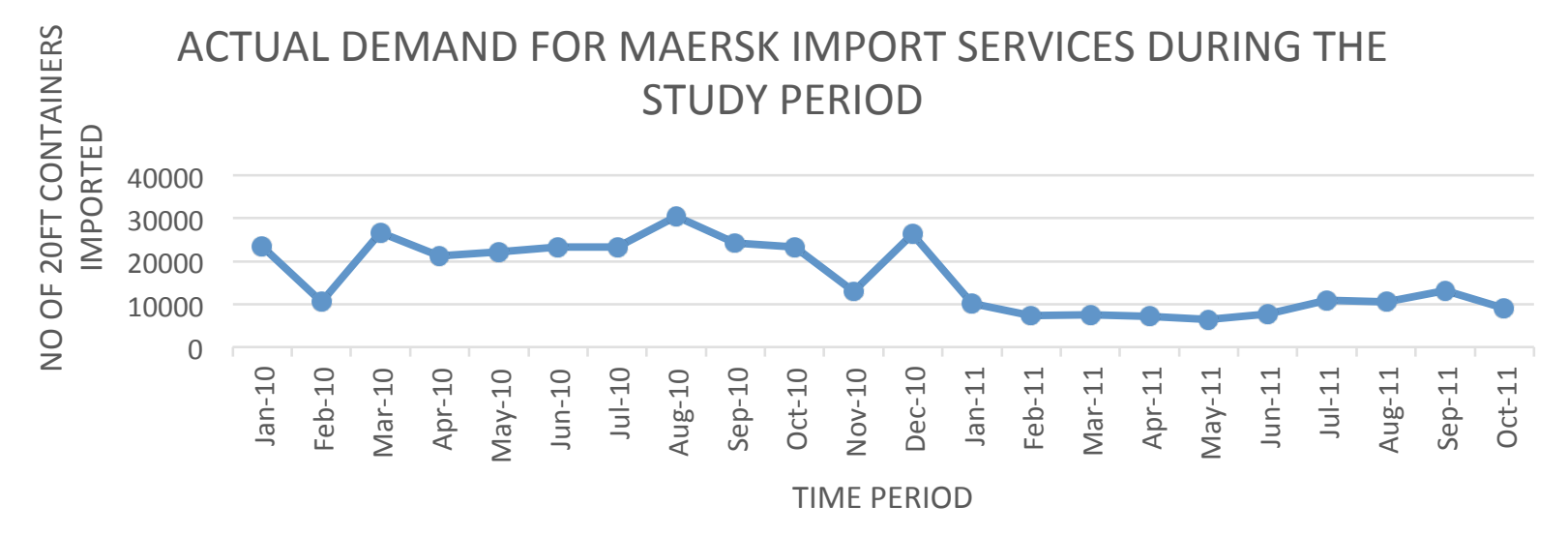

Figure 4.2: Time series plot of the demand for Maersk Ltd.'s export services over the study period.

The plot for the demand for imports services is not significantly different from the export. The demand for import services is obviously far higher than the demand for import services. The pattern is horizontal, and the same general decreasing trend from January 2011 is presents.

As already noted, the model of forecasting to be used depends on the pattern exhibited by the time series plot. Since the time series plots above indicate a horizontal pattern for both the import and exports data, Anderson et al, (2012) recommend three forecasting methods that are appropriate for data of this kind. These are the moving average method, weighted moving average method and the exponential smoothing method. In order to determine which the best forecasting method is, all of the three will be applied on the data values.

\section{The Moving Average Technique}

From our interview with the managers, this is the technique currently employed by the company in forecasting for the demand of their services. This forecasting method simply averages the data values recorded over a selected time period to compute the forecast for the next period. Currently the practice in the firm is to average the actual demand for the past 6 months and use it as the forecast for the 7th month. This is known as a 6 period moving average.

In general, the Moving Average is given by

$$
\text { Moving average }=\frac{\sum(\text { most recent } n \text { data values })}{n}
$$

In order to present the current situation of forecasting in the Company, the 6-period moving average was employed to compute for the next period's forecast. The output for this forecasting method using excel QM is presented in Table 4.1 in Appendix. 


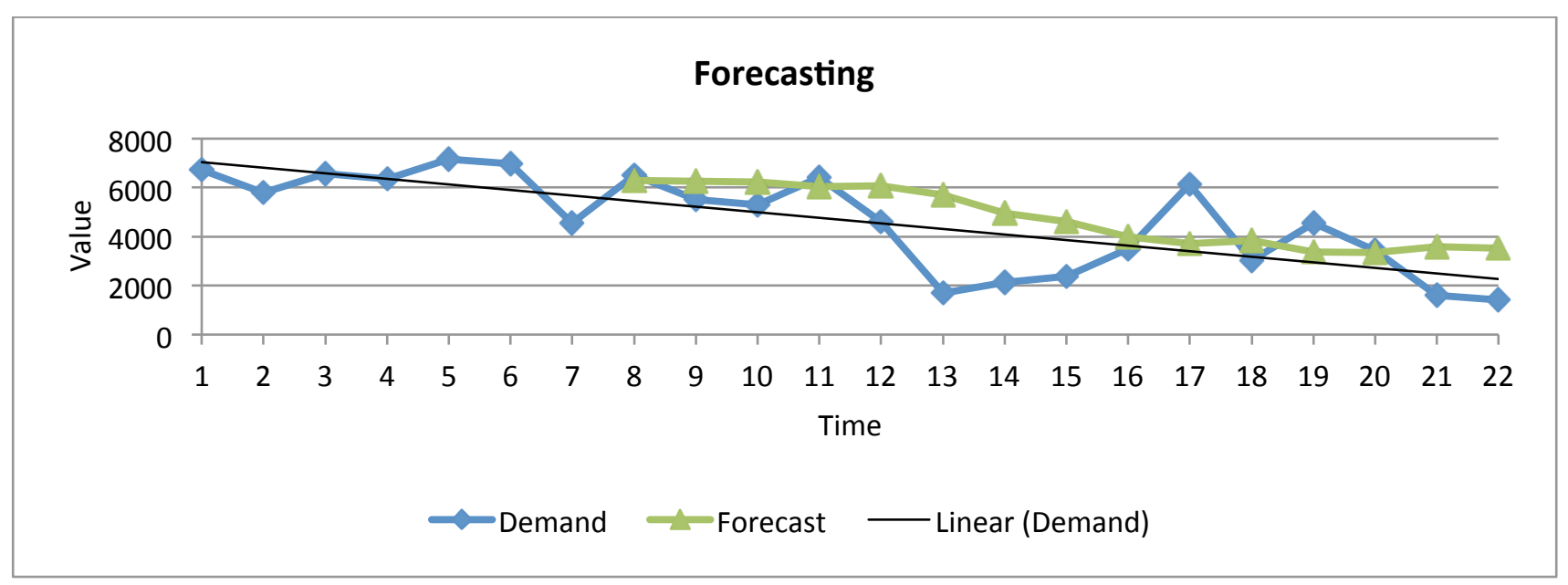

Figure 4.3 a graphical representation of Actual vs. Forecast Values for Maersk Line's export using the 6 period Moving Average.

4.3.1 Forecast for imports using the 6 period moving average

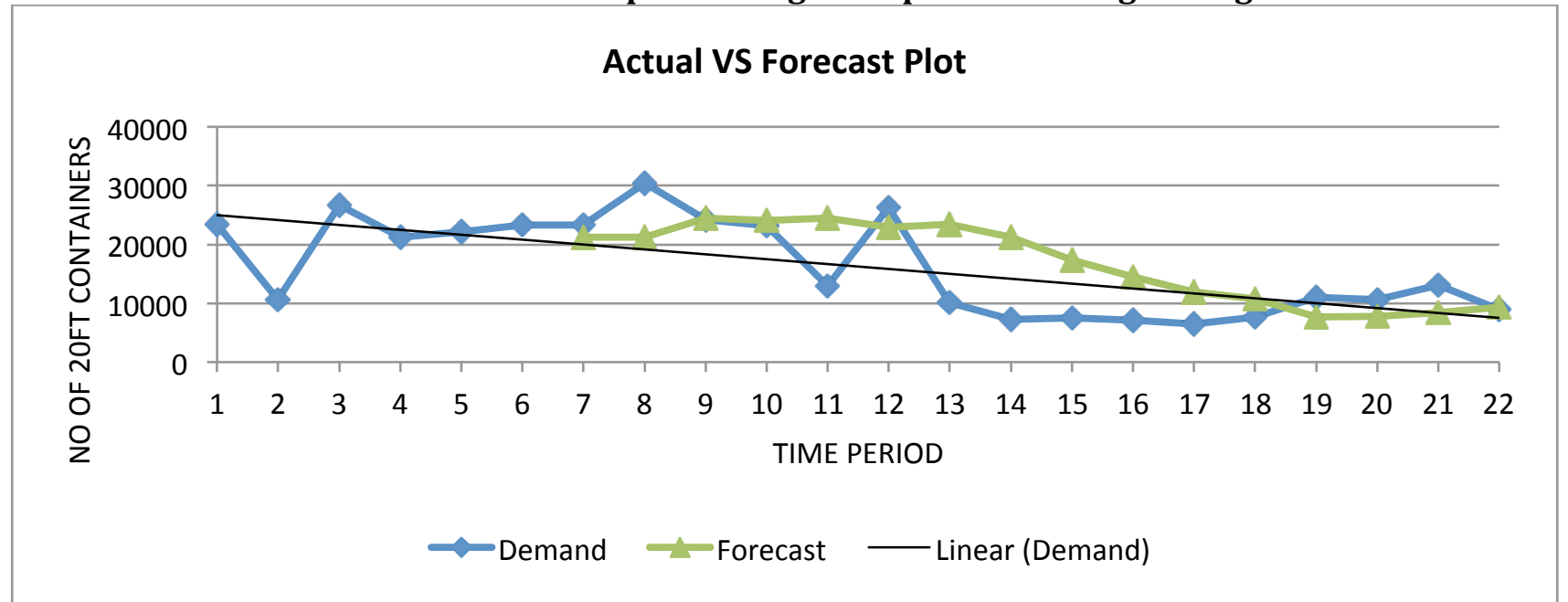

Figure 4.4: Figure 4.3 a graphical representation of Actual vs. Forecast Values for Maersk Line's import using the 6-period Moving Average.

\section{Summary of Results from Using the 6-Period Moving Average}

Figure 4.3 and 4.4 indicates that the 6 period moving average is trying to smooth the variations in the demand for both imports and exports. For both categories, the model does a good job from the beginning of the time period and the end of the time periods where the forecast errors are relatively smaller. However, the forecast errors in the middle are relatively higher due to the increasing and rapid demand variations in the center. Also, the trend line for demand indicates a general decrease in demand over time. The means squared error (MSE) and the Mean Absolute Percentage Errors are also presented in the table. Particularly, the MAPE figures are relatively high since error percentages above $50 \%$ often make a forecasting model undesirable.

Most often when the demand values exhibit irregular patterns, using short period forecasting gives a more accurate forecasting values. In such instances a 3-period moving average should be used instead of the 6-period moving average currently in use. Duell, (2001) emphasized that using longer periods in forecasting using moving averages would decrease the susceptibility of demand and this was very evident using a six-month moving average. When a smaller period was chosen, forecasted demand was nearer to actual than in a six-month moving average. To 
demonstrate this, the three-period moving average was used and the results are reported in the Table 4.3 in appendix

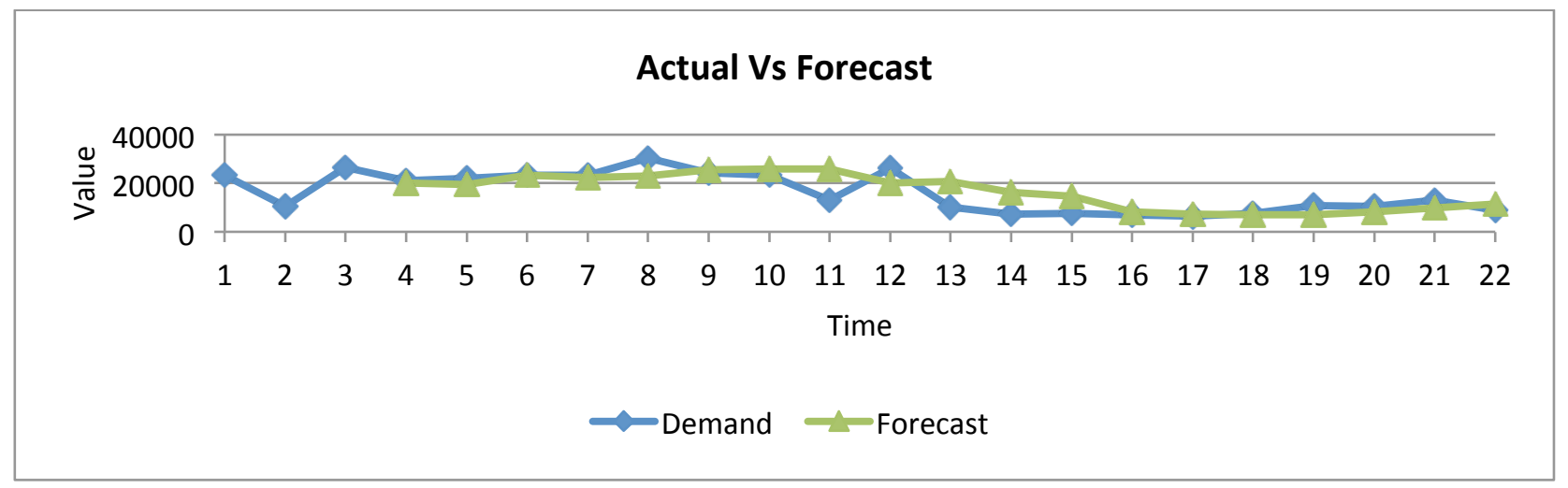

\section{Three-period moving average forecast for import data}

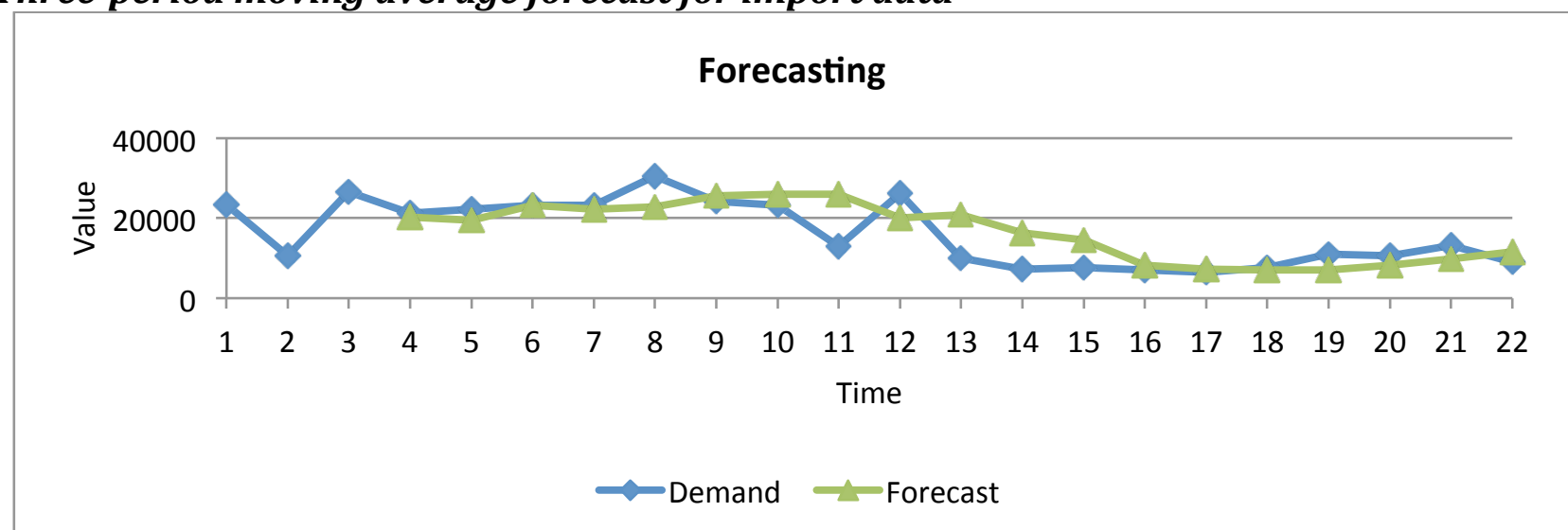

From the resulting tables and the graphical representation for both import and export data, the three period moving average fits the forecast values to the actual better than the 6-period moving average estimation. A comparison of all models used in the study will be presented later in the chapter.

\section{Using the Weighted Moving Average Forecasting Method}

The moving average method above assumes that all the past data has equal power in predicting the forecast value for the next period. In real world however, is often safer to assume that the immediate past data values is more powerful in predicting the future value than the distant past. Especially for the type of demand like Maersk which exhibits random fluctuations at some point, using the weighted moving average will often give better forecasting values. In this method, weights are going to be assigned to the past periods such that more weight will be given to the immediate past month and the least weight to the most distant month.

As already stated above, data values that exhibit rapid random patterns are not good candidates for long range time series methods. Due to this reason the weighted moving average is going to be computed on a three period basis. The assigning of weights are somewhat arbitrary, however the highest weight must be for the immediate past month and the lowest weight must be for the distant month. For this analysis the researchers have chosen a weight of 10, 2 and 1 respectively for the data values in order of recent values. This has been done to help smoothen the rapid fluctuations that occur at certain stages in the time series by giving a huge weight to the most recent value. 
The general formula for estimating the weighted moving average is given by:

$$
F_{t+1=\frac{\sum(\text { weight in period } i)(\text { Actual value in period } i)}{\sum(\text { Weights })}}
$$

The Table 4.5 (see appendix) presents the output for both the export and the import data after using the three period moving average with the weights stated above and the figures of it are shows below.
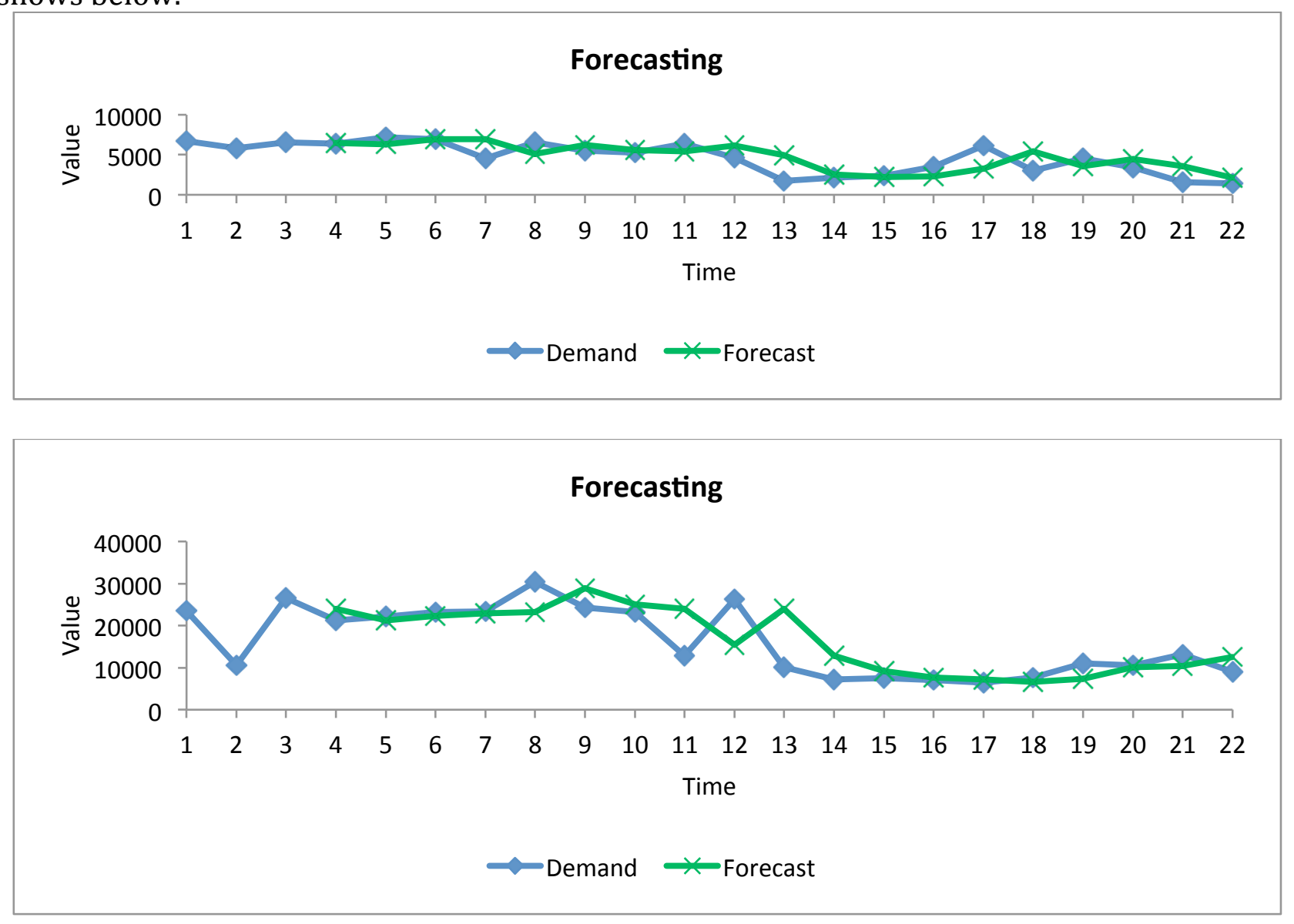

\section{Summary of Output from the Use of the 3 Period Weighted Average}

From the graphical representation of actual vs. forecast values, the 3 period weighted moving average seems to fit forecast values closer to the actual values than the previously used simple moving average. This is very visible in the centre of the data where there was large variation between the actual and forecast values in the first model used. A discussion on model choice will be presented later. Percentage errors associated with using weighted moving average are smaller than that of moving averages (Duell, 2001). This was made evident when the MAPE of the weighted moving average was calculated. There was a decrease in the MAPE values using weighted moving averages than simple average.

\section{Using the Exponential Smoothing Method}

The final method to be used for this time series is the exponential smoothing method. This forecast methods require the least time series data as compared to all the others used so far. As such it is better suited for data like this one which exhibits rapid random variations at this point. As already shown by the results from the weighted moving average, a focus on the most recent data values provide better forecast results for this data.

The general exponential equation formula is given by:

$$
F_{t+1}=\alpha Y_{t}+(1-\alpha) F_{t}
$$


Where

$$
\begin{aligned}
& F_{t+1}=\text { forecast of the time series for period } t+1 \\
& Y_{t}=\text { actual value of the time series in period } t \\
& F_{t}=\text { forecast of the time series for period } t \\
& \alpha=\text { smoothing constant }(0 \leq \alpha \leq 1)
\end{aligned}
$$

The selection of the smoothing constant is somewhat arbitrary, just like the weight selection in the moving average. However, we have use the QM for windows software to select a smoothing constant that will give the lowest MSE and MAPE values. The constant is 0.80 . Therefore the table below provides forecast values for export data using an alpha $(\alpha)$ value of 0.80 as the smoothing constant. According to Duell (2001), larger alpha values emphasize recent levels of demand and result in forecasts being more accurate and as such a larger alpha was chosen with the assistance of QM software.

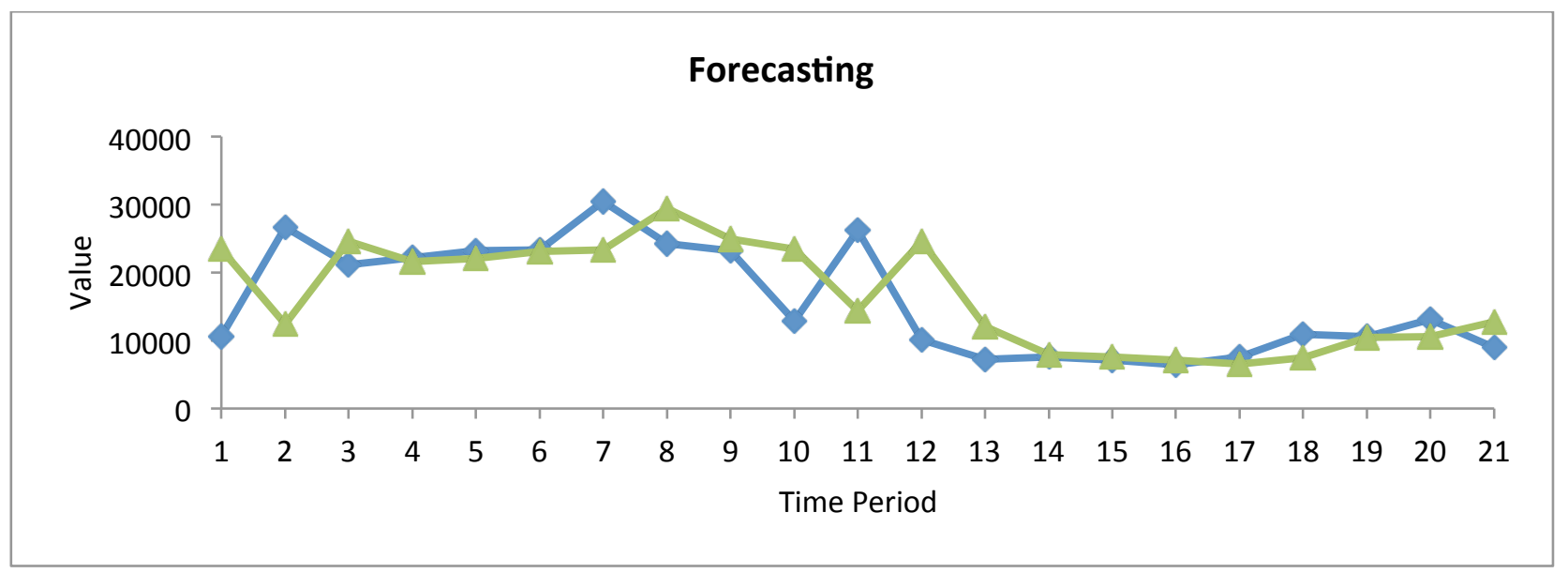

\section{Comparing the Forecasting Models}

The basis comparing the forecasting model is on the basis of the level of variation of the forecast values from the actual data values. Therefore, the MSE and MAPE values will be used as the basis for selecting the best forecasting. Due to the fact that the MSE and MAPE provide a figure of the error associated with the forecasting techniques, the best forecasting method will always be the one that provides the lowest values of MSE and MAPE. Jacobs and chase (2008); Duell (2001); Gardner (2006) have reviewed that exponential smoothing is the best method in calculating forecast with time series data. This research also supported their report because when the other techniques were used, the method that revealed the least MAPE was the exponential smoothing method. The comparison will be made in terms of the data categories

\begin{tabular}{|c|c|c|}
\hline MODEL & $\begin{array}{l}\text { Mean Squared Error } \\
\text { (MSE) }\end{array}$ & $\begin{array}{lr}\text { Mean } & \text { Absolute } \\
\text { Percentage } & \text { Error } \\
\text { (MAPE) } & \\
\end{array}$ \\
\hline 6 Period Simple Moving Average & 3341971.069 & $59.59 \%$ \\
\hline 3 Period Simple Moving Average & 2669060.895 & $46.34 \%$ \\
\hline 3 Period Weighted Moving Average & 2378745.3 & $39.63 \%$ \\
\hline Exponential Smoothing & 2131647 & $35.06 \%$ \\
\hline
\end{tabular}
i.e. for export and import data.

\section{Model Comparison for the Export Data}

The table below provides the different models used and their associated MSE and MAPE values.

From the data in the table above, it is evident that all the methods presented in the study provide a better forecast accuracy than the one currently in use by Maersk Line (the 6 period moving- average). This is because the errors associated in the presented models are lower than 
using the 6-period moving average. However, the Exponential smoothing method with a smoothing constant of 0.80 is recommended to the firm for future forecasting purposes since it is the model that provides the lowest values for MSE and MAPE.

The results from the data confirms the research conducted by Gardner \& McKenzie (1985), Gardner (2006); Jacob and Chase (2008) and Duell (2001) that exponential smoothing would give the least MAPE when the right smoothing constant is used. The exponential smoothing method recorded a MAPE of $35.06 \%$ whereas the method used by Maersk recoded a MAPE of $59.59 \%$. Duell (2001) stated that moving averages always produced a forecast with the highest percentage error which was evident in our analysis.

\section{Model Comparison for Import Data}

The table below provides the different models used and their associated MSE and MAPE values.

\begin{tabular}{|l|l|l|}
\hline MODEL & $\begin{array}{l}\text { Mean Squared } \\
\text { Error (MSE) }\end{array}$ & $\begin{array}{l}\text { Mean Absolute } \\
\text { Percentage Error (MAPE) }\end{array}$ \\
\hline 6 Month Simple Moving Average & 52353852.01 & $57.87 \%$ \\
\hline 3 Month Simple Moving Average & 30110716.12 & $34.91 \%$ \\
\hline 3 Month Weighted Moving Average & $\mathbf{3 0 8 9 5 4 6 4 . 7}$ & $\mathbf{2 9 . 8 2 \%}$ \\
\hline Exponential Smoothing & 44802330 & $32.87 \%$ \\
\hline
\end{tabular}

Similar to the result found in the forecasting for exports, the error associated with their current method is far higher than with the models presented in this study. The 3 period weighted moving average with weights 10,2 and 1 is recommended as the best forecasting method since it can reduce the percentage forecast error from the original $57.87 \%$ to as low as $29.82 \%$. Therefore for the purpose of forecasting demand for imports, the firms should use the 3 period weighted moving average with the weights listed above. The pattern or trend that is exhibited would determine the type of forecasting method to be used. The results for imports also reviewed that the simple average had the highest MAPE.

\section{Impact of the Models Used in their Operations}

According to MAERSK there are two basic models used in forecasting their operational demand, the models are: Simple Average and Moving Average. Maersk line in their quest to reduce clerical works adopted the above methods to enable them achieve the said objective.

Maersk made it clear to us that the above techniques were easy and the most simple to operate with. These were adopted to ensure that every employee even those with no technical skill in forecasting can read and interpret the outcome which will go a long way to positively influence effectiveness and efficiency of the logistics activities. Also these techniques were beneficial to MAERSK line since materials are received in uniform lot quantities. It was discovered that the operations of Maersk line Ghana are linked to the Global E-Business of the mother company, AP Moller Maersk Group. The operations manager of Maersk line, reaffirmed it by saying:

"The Operational activities of Maersk line are such that wrong forecasting affects our operations drastically". In making critical organizational decisions, the company strongly relies on the forecasted demand in order to make vital decisions. In situations where the forecasted demand doesn't much with the actual, the company is not able to deliver the goods to the customer and this put a huge challenge on the firm. Maersk line has one of their shipping services known as 'Your promise. Delivered' and as such when customers consignments are not delivered on time, it poses a great challenge on management and employees. Stevenson (2007) affirms that the type of forecasting model employed by a firm affects the decisions of 
the firm. Moving averages and exponential smoothing are essentially short-range techniques, since they produce forecasts for the next period. Trend equations can be used to project over much longer time periods.

\section{Essential Link between Demand Forecasting and Capacity Planning.}

Capacity planning is the process of determining the production capacity needed by an organization to meet changing demands for its products/services. However, demand is specifically the actual quantity customers ordered. For a company to satisfy their customers, they should specifically analyze their actual demand with respect to their capacity. Again, management believe that:

'the need for capacity planning is to close the gap or the discrepancy between the capacity of an organization and the demands of its customers which is an essential link between demand and capacity planning that needs to be managed'.

This research revealed that there were some instances where that the actual demand of Maersk line from their customers exceeded the capacity they can offered. During capacity planning, management relies heavily on forecasted values of previous years to avoid a halt in the service processes and remain highly responsive which is one of their core values. Therefore inaccurate demand forecasting has a direct effect on capacity planning which is disastrous to operational success, responsiveness and efficiency.

In such a situation, management employs additional resources to cater for the excess demand. Some of the management decisions are to load consumer goods in a forty-foot container instead of the usual twenty-foot container, channel some of their excess demand to third parties like- DHL to transport on their behalf, hire part time workers. However the operations manager affirmed that excess capacity rarely occurs. Also the firm employs additional labor on part time basis to meet unexpected increase in demand. The operations manager said that in a situation where demand is lower than the available capacity, the idle capacity is not used to satisfy other firms' needs.

Demand forecasts are essential inputs for many business decisions they help managers decide how much supply or capacity will be needed to match expected demand, both within the organization and in the supply chain.

\section{SUMMARY OF FINDINGS}

From the information gathered, it was found out that there are periods that forecasted demand exceeds capacity of the firm.

Another important discovery was that, forecasts were critical for planning container positioning, for example, for exports when entering a major commodity season. The input for forecast comes from both loading and receiving ports.

The main objectives of firms are to be responsive or efficient or both. We realized that Maersk line preferred to be responsive and as such incur more cost by underutilizing their capacity. Maersk line Ghana does not utilize their idle capacity even though they affirm that they experience excess capacity. They assert that they want to be responsive to their customers.

It was realized that the six month moving average used by Maersk had the highest mean absolute percentage error. 
It was also found out that they did not keep records of the amount of sales lost when demand outstrips their capacity. They also had no records of the average cost incurred due to excess capacity. Their reason was that they were not in charge of the cost incurred since the mother company handles all the financial affairs globally.

In reviewing their forecasting models, the firm involved third parties to review their models. Also the demand values exhibited irregular patterns both in export and import figures as illustrated in fig. 4.1 and 4.2 .

\section{RECOMMENDATIONS}

Based on our findings, we suggest the following recommendations:

I. Maersk line Ghana should not use only one model to forecast for both exports and import data. We therefore recommend from our study that the organization should use exponential smoothing model of forecasting to forecast their export data only. The preferred Alpha or constant to be used in the smoothing method should be 0.8 . This alpha would give the firm the least percentage error. The preferred forecasting model for import should be a three-month weighted moving average. This would help the firm reduce the percentage errors in their forecasting instead of their six-month moving average. This is due to the fact that their pattern for their demand is irregular and therefore a shorter period for forecasting would be appropriate.

II. The staff of Maersk line Ghana should be taken through training in IT systems and software regarding forecasting in order to increase their knowledge in forecasting and help them make accurate forecasts. Since the firm emphatically stated that they make critical operational decisions and capacity planning with their forecast values, it would be prudent that they develop software and trained personnel to deal with their forecasting. This would help increase the effectiveness of their forecast results and aid in effective capacity planning. Some of these methods are outlined in the literature review in chapter two.

III. Also, we suggest that, the staff of Maersk Line Ghana should endeavor to calculate and keep records of the value of sales lost when demand outstrips capacity and the amount of cost incurred when there is excess capacity. This would help the company determine the loses they make at the branch level due to inaccurate forecasts and would enable them employ better forecast methods to increase their efficiency.

IV. Maersk line should utilize their idle capacity by transporting full truck load containers. They can sell their unutilized space to other shipping firms to avoid cost. The main objectives of firms are to be responsive or efficient or both. It was realized that Maersk line preferred to be responsive and as such incur more cost by underutilizing their capacity. Costs involved in idle capacity increased transportation cost, minimal profits, etc. to avoid these cost Maersk line should utilize their idle capacity fully.

V. Monitor the forecast. A forecast has to be monitored to determine whether it is performing in a satisfactory manner. If it is not, reexamine the method, assumptions, and validity of data, modify as needed and prepare a revised forecast.

\section{CONCLUSION}

From the findings above, it came to notice that demand forecasting place a very critical role in the success of many organizations in almost every industry with the maritime industry inclusive. Therefore the refusal or inability to accurately forecast demand would make the organization involved unable to meet customer demand effectively and would therefore be left behind in the industry within which they operate. Also the use or application of a wrong forecasting model would cause an inaccurate forecast demand which will eventually affect the 
capacity of the firm. This research assessed and identified critical issues in demand forecasting, recommended certain models and practices that can be used to maximize the benefits gained from forecasting demand effectively. The research study also identified the link between demand forecasting and capacity planning.

\section{Further Research Study}

It is therefore recommend that, further research should be conducted over a period of time in the maritime industries to improve upon the use and knowledge of demand forecasting methods in those industries especially in the service providing sectors. Study should also be done using more maritime industries to enhance the precision of the analysis and make it possible for stronger conclusions to be drawn from the research study.

\section{Refrences}

Corbett, J. J., and J. J. Winebrake (2007), Sustainable Movement of Goods: Energy and Environmental Implications of Trucks, Trains, Ships, and Planes, Environmental Management, November.

The Impacts of Globalisation on International Maritime Transport Activity (2008). Global Forum on Transport and Environment in a Globalising World 10-12 November 2008, Guadalajara, Mexico

Juma, K. (The Impact of Inventory Management and Performance of Private Organizations in Uganda. A Case Study of Coca- Cola Mbarara Plant in Mbarara Municipality

Chendroyaperumal, C. (2009). DEMAND FORECASTING TECHNIQUES: AN EVALUATION. National Institute of Management Studies. Retrieved March 30, 2015, from www.researchgate.net.

Det Norske Veritas (DNV) (2004). Corporate Social Responsibility and the Shipping Industry, Project Report, No 2004-1535, Revision No1

Duell, T. (2001). Forecasting Demand in a Changing Economy, A Formulations Pro, Inc. White Paper, pages 4-8.

Gardner Jr., E. S. (2006). Exponential smoothing: The state of the art Part II. International Journal of Forecasting, 22, 637-666.

Gardner Jr., E.S. \& McKenzie, E. (1985) Forecasting trends in time series, Management Science, 31, 1237-1246.

Hope, C. A. and Muhlemann, A. P., (1997) Service Operations Management: Strategy, Design and Delivery, Prentice Hall, Hemel Hempstead, 352pp.

Huang Y. and Lee, Y. (2011). Accurately Forecasting Model for the Stochastic Volatility Data in Tourism Demand, Scientific Research, an Academic Publisher, Vol.2 No.5, November 2011

Jacobs, R.F. and Chase, B. R., (2008). Operations and supply management: the core, Book, McGraw-Hill/Irwin series operations and decision sciences

Kumar, S., and J. Hoffmann (2002), Chapter 3 Globalization: the Maritime Nexus, in Handbook of Maritime Economics and Business, pp. 35-62, Informa, Lloyds List Press, London

Korpela, J. and M. Tuominen, 1996. "Inventory Forecasting With a Multiple Criteria Decision Tool." International Journal of Production Economics, 45: 159-168.

Krumwiede, D.W. \& Sheu, C.* (2002). A model of reverse logistics entry by third-party providers, Omega, 30(5), 325-333.

Magirou V., Psaraftis, H. and Christodoulakis, N., (1992), Quantitative Methods in Shipping: A Survey of Current Use and Future Trends, Report No. E115, Center for Economic Research, Athens University of Economics and Business.

Nurrahman, A., (2012). Definition of Demand Forecasting, Article BlogNotions

Phelan, M. and McGarraghy, S., (2006) Clustering \& Demand Forecasting in Telecommunications Supply Chains 3rd CEMS Research Seminar 2006 SUPPLY CHAIN MANAGEMENT: THE CHALLENGE OF OUTSOURCING \& OFFSHORING SUPPLY CHAIN ACTIVITIES Riezlern, Austria, , 25-JAN-06 - 29-JAN-06 
Mensah, J., \& Anim, S. K., \& Obeng, F., \& Peprah, J. A. (2016). Demand Forecasting in the Maritime Industry, a Case of Maerskline Ghana. Archives of Business Research, 4(1), 192-208.

Progoulaki M., 2005, "Strategic Management of Multicultural Shipping Crews: choice of research methodology", 12th Panhellenic Undergraduate Intensive Seminar- Conference for Doctoral Students (Anogia Summer Schools): Methodological Issues of Research in Social Sciences, Rethymno, Crete, Greece, November 18-21.

Rodrigue, J.P. (2010). Maritime Transportation: Drivers for the Shipping and Port Industries, Forum Papers, International Transport Forum 2010 Transport and Innovation Unleashing the Potential

Sletmo, G. K. (1989) Shipping's Fourth Wave: Ship Management and Vernon's trade cycles, Maritime Policy and Management 16 (4), pp. 293-303

Tseng, Y., W.L. Yue and M.A.P. Taylor, 2005. The role of transportation in logistics chain, 5: 1657-1672.

Turban, et al., (2007). Deision Support Systems and Intelligent Systems, 7th edition, pp 816-828 Prentice-Hall of India

Yin, R.K., 2003. “Case Study Research: Design and Methods: (Applied Social Research Methods, Volume 5)” SAGE Publications, Inc; Third Edition edition Newbury Park, Calif.: Sage. ISBN-13: 978-0761925538 